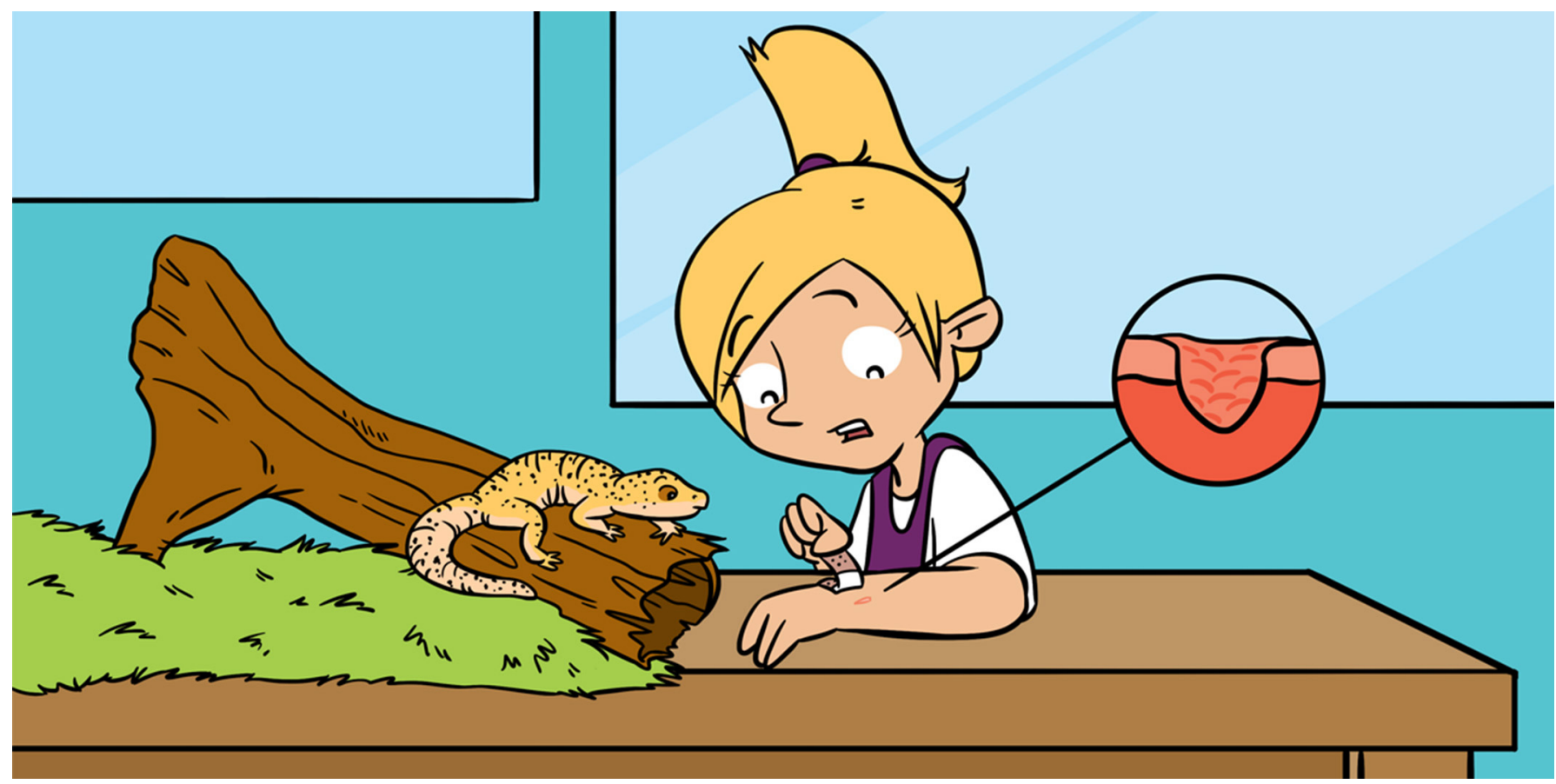

\title{
LESSONS FROM LIZARDS: HOW SCALY SUPERHEALERS CAN HELP HUMANS
}

\author{
Noeline Subramaniam ${ }^{1,2}$, Kathy Jacyniak ${ }^{3}$, Rebecca P. McDonald ${ }^{3}$ and Matthew K. Vickaryous ${ }^{3 *}$ \\ ${ }^{1}$ Institute of Medical Sciences, University of Toronto, Toronto, ON, Canada \\ ${ }^{2}$ Keenan Research Centre in the Li Ka Shing Knowledge Institute, St. Michael's Hospital, Toronto, ON, Canada \\ ${ }^{3}$ Department of Biomedical Sciences, Ontario Veterinary College, University of Guelph, Guelph, ON, Canada
}

\section{YOUNG REVIEWER:}

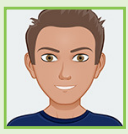

NOAH

AGE: 10
Regeneration is the ability to regrow injured or missing body parts. While you might think that regeneration is science fiction or a superpower, it is surprisingly common to many types of animals, including lizards. So why are lizards superhealers? What organs can lizards repair, and what can we learn from lizards to help people? To answer these and other questions, we take a closer look at our scaly neighbors. Our research reveals new ways to look at old problems, such as how to repair skin, the heart and even the brain. Lizards and other species offer important lessons for how to heal, and may one day offer new methods for advancing human health.

\section{LIZARD SUPERHEALERS}

What if, after an accident, you could regrow parts of your body? What if you could repair your injuries without going to the hospital? It may 
Figure 1

Scars in skin. A key participant in wound healing are blood vessels. (A) Scar Formation in Mammals-Following an injury in mammals there are tons of thin-walled blood vessels that form. These vessels lack support cells and thus, are often leaky. The structures of the skin like hair follicles, nerves and glands, are not replaced following injury. (B) Skin Regeneration in Lizards-In contrast, lizards form few blood vessels following injury. These vessels do have support cells and thus, are not leaky. The structures of the skin are regenerated following injury.

\section{REGENERATION}

The ability of a cell, tissue, or organ to almost perfectly replace that which has been lost, restoring structure, and function.

\section{A) Scar Formation in Mammals}
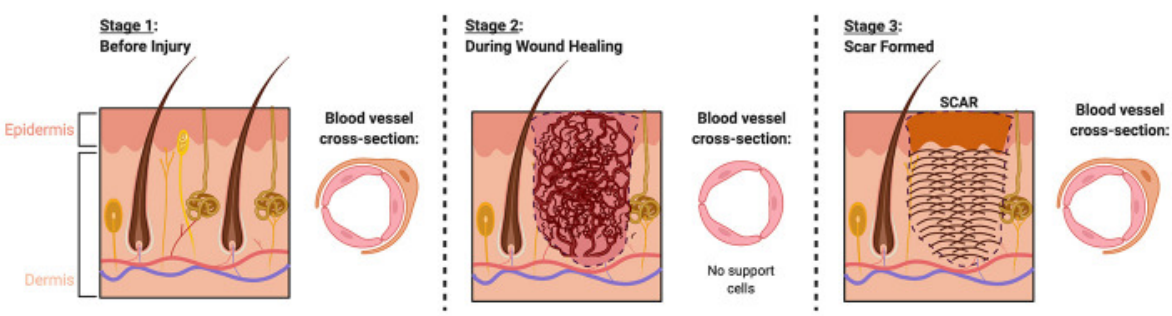

B) Skin Regeneration in Lizards
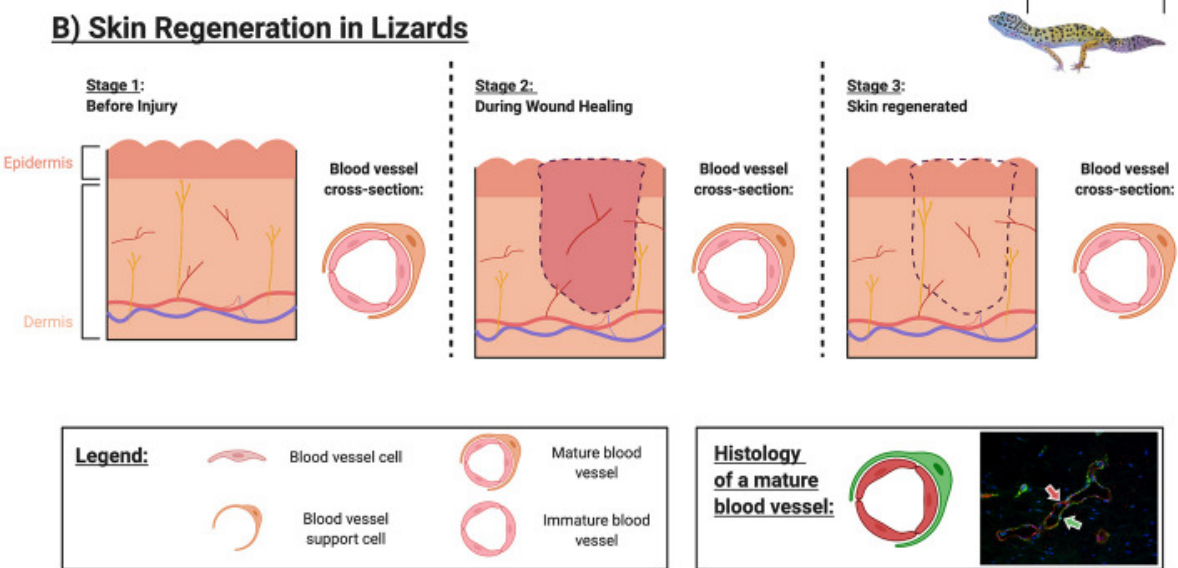

Figure 1

sound like science fiction, but it happens to animals in the wild all the time.

You probably know that some lizards can regrow their tails. If caught by a predator, many lizards, like the leopard gecko, can detach a portion of their tail. With the predator busy eating the tail, the lizard can escape. The newly tailless lizard can then regrow or regenerate a replacement tail [1]. But lizards can do more than regenerate their tails. Scientists are beginning to learn that some lizards can also regenerate parts of other organs, like the skin, heart, and brain. So why are some animals like lizards superhealers while other animals, including people, are not?

\section{WHAT HAPPENS WHEN HUMAN SKIN GETS INJURED?}

We have all experienced scrapes, burns and cuts, so it is no surprise that the skin is our most frequently injured organ. The skin does more than keep all our insides together. It helps us regulate body temperature, it provides protection against harmful rays from the sun, and it can detect heat, cold, pain, and pressure (touch).

In all vertebrates (animals with backbones, including fish, reptiles, and mammals) the skin is made of two main layers: the epidermis and the dermis (Figure 1). The epidermis is the outer layer and the part that we normally see. Beneath the epidermis is the dermis, which is responsible 
SCAR

The inability of a cell, tissue, or organ to replace that which has been lost, resulting in a loss in function.

\section{COLLAGEN}

An important structural protein in the body. Collagens are the most abundant proteins in the body. for many of the skin's functions. It contains the blood supply to the skin, and has nerves, hair follicles, and sweat glands.

Injuries that cut the dermis result in bleeding and sometimes, scar formation. Scars happen when the dermis is repaired, but the repair is not perfect (Figure 1A). For example, in humans, scarred skin does not regrow hair or sweat glands. Scarred skin is also weaker than uninjured skin. The main protein in skin is called collagen. In uninjured skin, collagen looks like it is woven together, making a zigzag pattern. This zigzag pattern allows the skin to stretch. In scarred skin, the zigzag pattern is lost and instead collagen is arranged into parallel layers. These layers of collagen do not stretch, making the scars more likely to tear apart.

\section{SOME SPECIES CAN REGENERATE SKIN}

In lizards, injuries to the skin are healed without scarring. That is, the skin is completely regenerated (Figure 1B). In fact, it is pretty much impossible to locate the wound site once healing is complete. So, what makes lizards different?

Interestingly, all major events that take place during scar formation in mammal skin also occur during skin regeneration in other species. The big differences are how soon wound healing begins after injury, how long healing takes, and the number of cells involved. Regenerating skin typically heals quicker than a similar-sized wound that scars. While it only takes a leopard gecko about 5 days to re-form the epidermis, this process can take between 1 and 2 weeks in humans [2].

One of the key differences between scarring and regenerating skin involves blood vessels. Before scars are formed, the wound site first develops lots of small, thin-walled blood vessels (Figure 1A, stage 2). These blood vessels lack the multilayered structure of normal blood vessels and are sometimes leaky. In contrast, the wound site of regenerating skin develops fewer blood vessels, and the blood vessels that do form are multilayered, just like the blood vessels in uninjured skin (Figure 1B, stage 2). Some scientists believe that this difference in blood vessel formation is one of the main reasons human skin scars, while lizard skin regenerates.

\section{WHAT HAPPENS WHEN THE HEART GETS INJURED?}

The one muscle in the body that never gets a break is the heart. Unlike the muscles in the legs and arms that get to relax when we sleep or watch TV, the heart constantly works, day and night. The heart's job is to move blood around the body. Blood delivers oxygen and nutrients, and removes carbon dioxide and wastes, to and from every single 
Figure 2

Healing hearts. (A) The heart of all animals is made up of multiple types of cells, but the ones responsible for making the heart pump are cardiomyocytes. (B) Injury to the lizard heart leads to the loss of cardiomyocytes (loss of pink staining within the yellow line). Over time, these cells divide enough times to replace those that were damaged or lost (return of pink staining within the yellow line). In mammals,

cardiomyocytes cannot divide following heart injury and are instead replaced by a permanent scar made up of collagen.

\section{CARDIOMYOCYTE}

A muscle cell located in the heart that is responsible for making the heart pump.

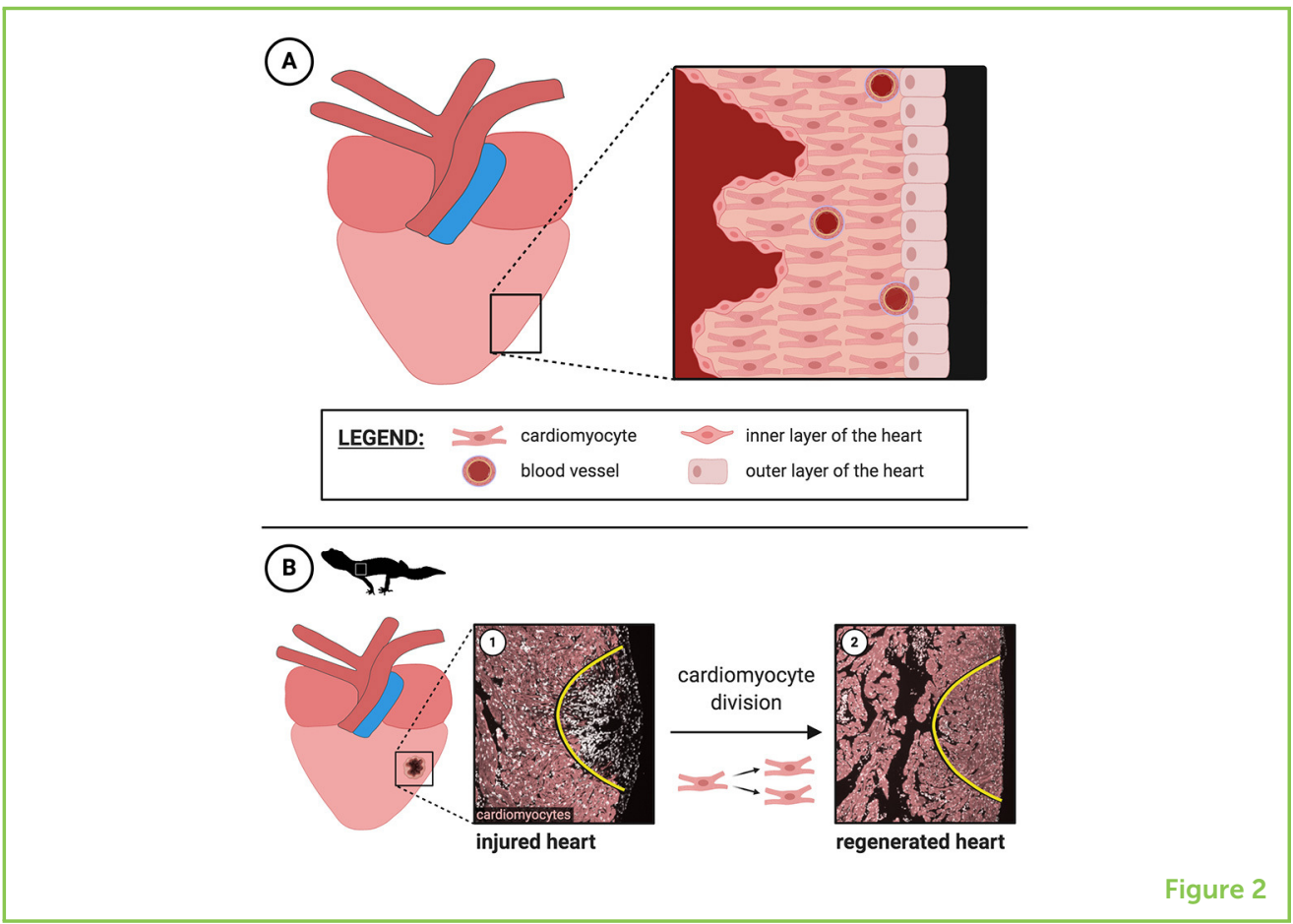

cell. This exchange of gases and nutrients is essential for keeping the body alive.

The heart is made of multiple types of cells, but the ones that do most of the work are the cardiomyocytes [3]. Cardiomyocytes are like microscopic motors, and billions of them work together to create the pumping action of the heart, which allows blood to be sent to all the cells and organs in the body. In humans and other mammals, injured cardiomyocytes are not regenerated (Figure 2A). For example, heart injury may happen when someone experiences a heart attack. In a heart attack, the blood vessels in the heart are blocked, preventing the heart from getting oxygen. The cardiomyocytes that die are replaced by collagen, creating a permanent scar. Since these scars do not stretch and squeeze like cardiomyocytes, a scarred heart needs to work much harder to pump blood.

\section{REGENERATING BROKEN HEARTS}

But this is not the case for all animals! Like skin, regions of the heart can be regenerated in some superhealing species. Instead of making scar tissue, some species of fish and lizards can regenerate lost cardiomyocytes (Figure 2B). So how does this happen? In these species, when the heart is injured, its existing cardiomyocytes divide to create new ones. These newly formed cells replace those that were lost due to injury. This leads to a heart that looks, but more importantly works, just like the original. 


\section{Figure 3}

Brand new brain cells (A) The main type of stem cell in the lizard brain is radial glia. Radial glia divide to make newborn neurons. (B) Each new neuron follows a direct path created by the radial glia to reach its final destination. (C) Once there, they mature and survive among the other (adult) neurons in the brain. In comparison, in mammals, stem cells make fewer neurons and are not as good at guiding them to their final destination.

\section{STEM CELL}

A cell that can divide to give rise to multiple different cell types, without getting used up itself.

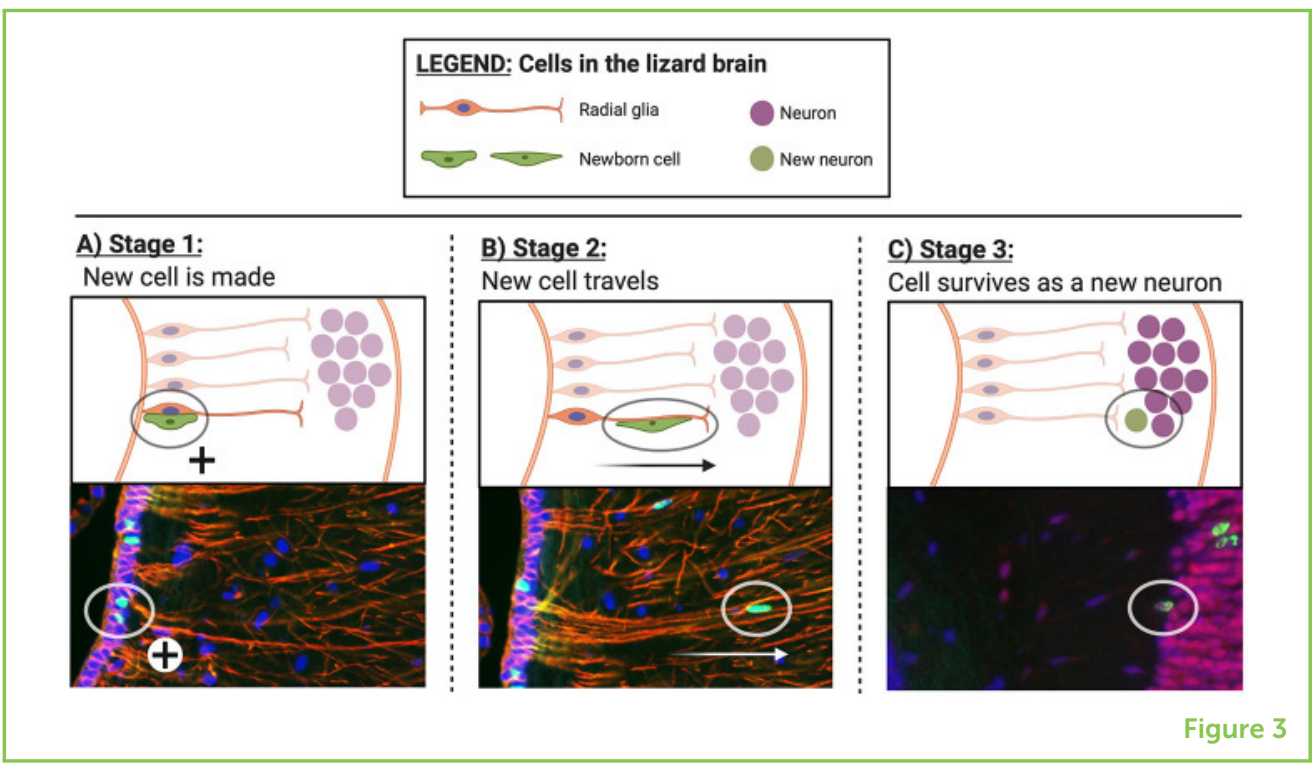

Why are some animals better at replacing lost cardiomyocytes than others? Their cells have the replication machinery on board to successfully divide, and the cell's environment support this division.

\section{WHAT ABOUT BRAIN INJURY?}

The brain acts as the control center of the body and oversees how we think, feel, move, and remember. Neurons are the brain cells responsible for most of the brain's functions. The job of neurons is to send information from one place to another. It was long assumed that once the body finishes growing, the brain stops growing and changing as well. We now know that the brain continues to change throughout life, and can even make new brain cells. This is what allows us to learn new things and make new memories. In the brain, stem cells are the source of new brain cells.

If our brains can change, how much change is possible? For example, if a person suffers from a brain injury or disease, can his or her brain be repaired? Although humans and other mammals have stem cells in their brains, these cells do not help much if the brain gets injured. When brain tissue is lost, it is not regenerated, which makes it hard for the brain to function like it did before. We do not fully understand why, but it seems like the reason we do not regenerate brain tissue is that our stem cells do not make many neurons. The neurons they do form can not always travel to the areas where they are needed and may not survive, even if they are able to get there. The result is that there are not enough neurons to replace the ones that were lost. 


\section{RADIAL GLIA}

Specialized stem cells that make new neurons in the brain and spinal cord.

\section{LIZARDS CAN REGENERATE BRAIN CELLS, TOO!}

Interestingly, some lizards can and do regenerate neurons (Figure 3). The new neurons travel to the site of injury, and when they arrive, they continue to survive [1]! Why can lizards regenerate brain cells after injury, while many other animals cannot?

One difference is the type of stem cells that are present in adult lizards but not in adult mammals. The stem cells that make neurons in lizards are called radial glia [4]. Radial glia are found in mammals before birth, but they disappear shortly after we are born. Lizards keep their radial glia, even as adults. Not only are radial glia really good at making neurons, but they also have long outgrowths that the new brain cells climb along until they get to their final destination. The new brain cells eventually become new neurons that work just as well as the older neurons around them.

\section{LESSONS FROM LIZARDS}

When scientists try to answer particularly difficult questions, they may turn to subjects that seem unexpected. Lizards probably are not the first thing we would think of if we had an injury to the skin, heart, or brain. However, by studying all kinds of organisms, scientists can better understand the ways we are similar to, and the ways we are different from, other organisms. For instance, some animals scar, whereas others regenerate. If we want to improve how humans heal after injury, a great place to look is toward other animals that are great at healing themselves! As scientists continue to study and better understand the biology of regeneration, this research will enable the development of therapies and treatments to improve human health. The lessons learned from lizards may bring us one step closer to becoming superhealers too!

\section{REFERENCES}

1. Jacyniak, K., McDonald, R. P., and Vickaryous, M. K. 2017. Tail regeneration and other phenomena of wound healing and tissue restoration in lizards. J. Exp. Biol. 220:2858-69. doi: 10.1242/jeb.126862

2. Subramaniam, N., Petrik, J. J., and Vickaryous, M. K. 2018. VEGF, FGF-2 and TGF $\beta$ expression in the normal and regenerating epidermis of geckos: implications for epidermal homeostasis and wound healing in reptiles. J. Anat. 232:768-82. doi: 10.1111/joa.12784

3. Jacyniak, K., and Vickaryous, M. K. 2018. Constitutive cardiomyocyte proliferation in the leopard gecko (Eublepharis macularius). J. Morphol. 279:1355-67. doi: 10.1002/jmor.20850

4. McDonald, R. P., and Vickaryous, M. K. 2018. Evidence for neurogenesis in the medial cortex of the leopard gecko, Eublepharis macularius. Sci. Rep. 8:9648. doi: $10.1038 / \mathrm{s} 41598-018-27880-6$ 
SUBMITTED: 16 September 2020; ACCEPTED: 29 June 2021;

PUBLISHED ONLINE: 28 July 2021.

EDITED BY: Michelle Juarez, Howard Hughes Medical Institute (HHMI), United States

CITATION: Subramaniam N, Jacyniak K, McDonald RP and Vickaryous MK (2021) Lessons From Lizards: How Scaly Superhealers Can Help Humans. Front. Young Minds 9:606902. doi: 10.3389/frym.2021.606902

CONFLICT OF INTEREST: The authors declare that the research was conducted in the absence of any commercial or financial relationships that could be construed as a potential conflict of interest.

COPYRIGHT @ 2021 Subramaniam, Jacyniak, McDonald and Vickaryous. This is an open-access article distributed under the terms of the Creative Commons Attribution License (CC BY). The use, distribution or reproduction in other forums is permitted, provided the original author(s) and the copyright owner(s) are credited and that the original publication in this journal is cited, in accordance with accepted academic practice. No use, distribution or reproduction is permitted which does not comply with these terms.

\section{YOUNG REVIEWER}

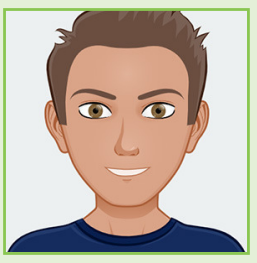

\section{NOAH, AGE: 10}

Hi! My name is Noah. I am 10 years old, and I just started 5 th grade. Ever since I was 3 years old, I have wanted to become an astronaut. I know a lot about space, aviation, science, and history. I love to read and learn new things. I also like playing with my cousins and friends and participating in a local EAA youth chapter.

\section{AUTHORS}

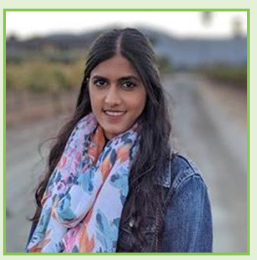

\section{NOELINE SUBRAMANIAM}

Noeline is a third year Ph.D., student at the University of Toronto, studying epigenetics and vascular biology. She is trying to better understand how and why blood vessels are affected in disease. Noeline began her academic career at the University of Guelph, completing her M.Sc., in regenerative biology. Using leopard geckos, she identified some of the proteins active in wound closure during skin regeneration. She is an active science communicator, sharing science and stories of her Ph.D., journey on Instagram (@thespicyscientist). In her spare time, she enjoys painting, watching reality TV, and spending time with her friends and family.

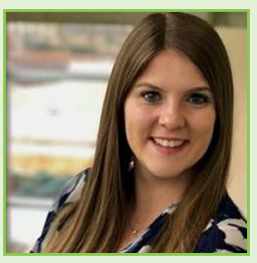

\section{KATHY JACYNIAK}

Kathy is a fourth year Ph.D. student at the University of Guelph, studying heart regeneration in the leopard gecko. Her main research interest is understanding the relationship between heart structure and function before and after injury. Kathy first started research as a M.Sc., student at the University of Guelph, and her project focused on identifying features in the gecko heart that are shared with animals that 

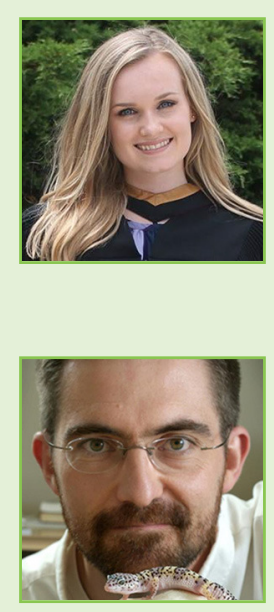

can regenerate their hearts. She volunteers for science outreach events regularly and is a mental health advocate for graduate students in her college. In her spare time, Kathy enjoys spending time outdoors.

\section{REBECCA P. MCDONALD}

Rebecca is a third year veterinary student at the Ontario Veterinary College. Before beginning vet school, Rebecca completed an M.Sc. studying stem cells in the leopard gecko brain. She now hopes to treat exotic animals (like lizards!) as a veterinarian one day. Outside of school, Rebecca enjoys volunteering with the birds at her local aviary. She shares her home with two dogs and parrot.

\section{MATTHEW K. VICKARYOUS}

Matt is an associate professor in the Department of Biomedical Sciences at the University of Guelph. He is a regenerative biologist whose research seeks to understand why some species are able to replace tissues, but others cannot. Matt completed an M.Sc., at the University of Calgary, where he studied a group of dinosaurs known as ankylosaurs. He then moved to Dalhousie University (Halifax) to study alligators. Matt returned to Calgary as postdoctoral fellow, where he began to study regeneration in lizards. Outside of the lab, Matt likes taking his family on adventures to find to reptiles and amphibians. ${ }^{*}$ mvickary@uoguelph.ca 